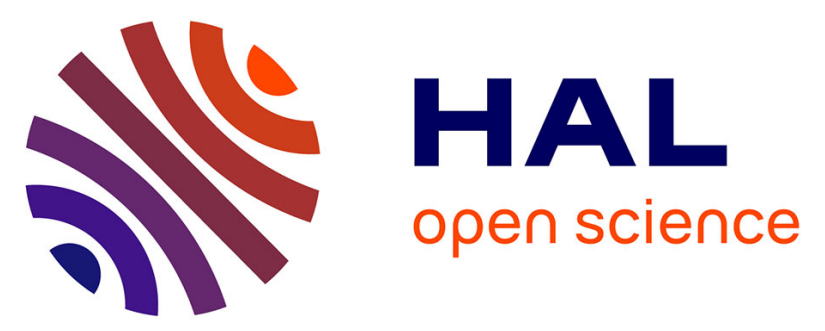

\title{
Comparative study of directional solidification of Al-7 wt\% Si alloys in Space and on Earth: Effects of gravity on dendrite growth and Columnar-to-equiaxed transition
}

Yuze Li, Nathalie Mangelinck-Noël, G. Zimmermann, L. Sturz, Henri

Nguyen-Thi

\section{To cite this version:}

Yuze Li, Nathalie Mangelinck-Noël, G. Zimmermann, L. Sturz, Henri Nguyen-Thi. Comparative study of directional solidification of Al-7wt\% Si alloys in Space and on Earth: Effects of gravity on dendrite growth and Columnar-to-equiaxed transition. Journal of Crystal Growth, 2019, 513, pp.20-29. hal02050669

\author{
HAL Id: hal-02050669 \\ https://hal.science/hal-02050669
}

Submitted on 27 Feb 2019

HAL is a multi-disciplinary open access archive for the deposit and dissemination of scientific research documents, whether they are published or not. The documents may come from teaching and research institutions in France or abroad, or from public or private research centers.
L'archive ouverte pluridisciplinaire HAL, est destinée au dépôt et à la diffusion de documents scientifiques de niveau recherche, publiés ou non, émanant des établissements d'enseignement et de recherche français ou étrangers, des laboratoires publics ou privés. 


\title{
Comparative Study of Directional Solidification of Al-7wt.\% Si Alloys in Space and on Earth: Effects of Gravity on Dendrite Growth and
}

\section{Columnar-to-Equiaxed Transition}

\author{
Y. Z. Li ${ }^{1}$, N. Mangelinck-Noël ${ }^{1, *}$, G. Zimmermann ${ }^{2}$, L. Sturz ${ }^{2}$, H. Nguyen-Thi ${ }^{1}$ \\ ${ }^{1}$ Aix Marseille Univ, Université de Toulon, CNRS, IM2NP, Marseille, France \\ ${ }^{2}$ ACCESS e.V., Intzestraße 5, 52072 Aachen, Germany
}

\begin{abstract}
Directional solidification experiments of grain refined $\mathrm{Al}-7 \mathrm{wt} . \% \mathrm{Si}$ alloy were carried out on Earth under normal gravity conditions (1g) and in the Material Science Laboratory on board the International Space Station in microgravity environment $(\mu g)$, to investigate the impact of the gravity on the solidification microstructure and the columnar-to-equiaxed transition (CET). The increase of the dendrite growth velocity imposed by the processing conditions during the experiments leads to a size decrease of the dendrite microstructure and to a more homogeneous eutectic distribution under both $1 \mathrm{~g}$ and $\mu \mathrm{g}$ conditions. A progressive CET is obtained in both samples implying the existence of an intermediate region after the inception position of CET defined as the end of growth of the columnar dendrites. However, a more progressive CET and longer dendrites aligned with the applied temperature gradient are observed in presence of gravity. This difference is attributed to the convective flow on Earth. On the one hand, it carries the grains that nucleate ahead of the columnar front away into the bulk liquid phase. On the other hand, it sweeps the solute away from the dendrite tip zone. Consequently, the blocking effect is diminished, allowing extended continuous growth of the elongated dendrites.
\end{abstract}

Keywords: B1. Alloys; A1. Directional solidification; A2. Microgravity conditions; A1. 
Convection; Columnar-to-Equiaxed Transition 


\section{Introduction}

The understanding and as a further step the control of the morphological development during solidification remains of tremendous interest in order to master the quality and performance of materials because of the relationship between the microstructures and the properties of the final materials. In metallic alloys, the solidified dendrite microstructure can be either elongated columnar or equiaxed, according to the solidification conditions [1]. Columnar-to-equiaxed transition (CET) is an important and common morphological transition, which frequently occurs during industrial processes such as ingot casting, welding and additive manufacturing. CET occurs when the amount and/or the size of equiaxed grains that grow ahead of the columnar front become sufficient to block the continuous columnar dendrite growth [2, 3]. The competition of dendrites at the solidification front is a complex topic, which involves mechanical effects as well as thermal and solutal interaction $[4,5]$.

The first analytical model to predict the conditions for CET was proposed by Hunt [4]. In this model, equiaxed grains are assumed to form by heterogeneous nucleation ahead of the dendritic columnar front in the undercooled liquid and to grow in this region. The extension of the undercooled zone and the maximum value of the undercooling depend on the thermal gradient and pulling rate. In Hunt's model, a steady-state criterion is added to predict the CET: fully equiaxed growth occurs when the equiaxed volume fraction is large enough to block the columnar growth. This criterion is often referred to as mechanical blocking. Despite some model hypothesis which can be discussed, this model agrees qualitatively well with experimental observations, in particular that fully equiaxed growth is dominant at low temperature gradient and high pulling rate. However, the model predictions strongly depend on two parameters: the nucleation undercooling (undercooling above which the particles become active) and the nucleus density. These parameters are not easily determined during experiments. 
Wang et al. [6] proposed a model where the solutal interaction between equiaxed grains was taken into account. However, the solutal interaction between the equiaxed microstructure and the columnar front is neglected, which implies to keep the mechanical blocking criterion to predict the CET. Martorano et al [7] extended this approach and developed a model where the solutal interaction between the equiaxed microstructure and the columnar front is successfully treated. The solute concentration ahead of the columnar front gradually increases due to the solute rejection from columnar and equiaxed grains and, consequently the columnar front undercooling decreases. If the reduction is sufficient to annihilate the columnar front undercooling completely, the columnar dendritic microstructure is stopped and CET takes place. In this approach, CET is a direct consequence of the solutal interaction between the equiaxed microstructure and the columnar front, so that it is referred as solutal blocking. Like in Hunt's analysis, this model depends on the two key parameters of refining particles, namely nucleation undercooling and nucleus density. Experimental evidences of both solutal interaction and mechanical blocking were brought by Reinhart et al [8], by means of synchrotron X-radiography to follow the dynamics of CET in situ and in real time.

During ground-based solidification, another crucial issue to be clarified is the role of gravity on the microstructure evolution, because gravity can affect all the factors linked to the above issues: thermal field, solute distribution and position and amount of new grains [3, 9, 10]. However, the solidification is a multi-scale and multi mechanisms process so that it is very difficult to deconvolute the different effects. Accordingly, microgravity experiments are the unique way to be able to study the effect of gravity by comparison with ground condition experiments [11]. Indeed, the two key ingredients in microstructure evolution during the solidification on Earth are the natural convection and grain motion due to buoyancy forces $[12,13]$. The natural convection, induced by any density differences in the melt in both horizontal and vertical direction $[14,15]$, is present in the liquid ahead of the solidification 
front as well as in the interdendritic region $[3,16,17]$, significantly modifying the solute and thermal fields [11, 18]. Consequently, convection is responsible for both micro- and macro-segregation [19-22]. Furthermore, the gravity can significantly affect the CET by two effects. First, the liquid flow ahead of the solidification front can dramatically modify the heat and solute conditions, leading to a significant modification of the undercooled region ahead of the columnar dendrites responsible for nucleation and dendrite growth [23]. Second, the interdendritic flow can favor the fragmentation by secondary branch neck remelting due to solute pile-up or transport of hot liquid at the level of the secondary branch neck [24, 25]. Such fragments can participate to the CET if they are transported from the columnar front into the undercooled region where they can continue to grow and possibly stop the advancement of the columnar front [26-28]. In the case of grain refined alloys, the liquid flow might also lead to the transportation of the grain refiners and therefore can affect the CET [29-31]. Finally, the newly nucleated equiaxed grains ahead of the columnar front are subjected to buoyancy force. Depending on the density difference between the grains and the surrounding liquid, they can either sediment, which can favor the blocking of the columnar front [3, 32], or float and be transported from the columnar front into the bulk liquid where they can be remelted [33]. In the latter case, the buoyancy force can inhibit the columnar to equiaxed transition [33-35].

Within this context, solidification experiment under microgravity conditions can provide unique benchmark data by effectively suppressing the gravity-driven phenomena and we can expect to achieve nearly diffusive conditions [36-38]. Within the ESA project CETSOL (Columnar to Equiaxed Transition in SOLidification processes), directional solidification experiments under both gravity (1g) and microgravity conditions ( $\mu$ g) [39, 40] have been carried out on selected aluminum-based alloys. Solidifications were carried out in the Material Science Laboratory (MSL) that was made available by the European Space Agency 
(ESA) on board the International Space Station (ISS), providing a platform for microgravity solidification investigations to clarify major scientific issues in solidification. The comparative study of directional solidification of Al-7wt.\% Si alloys in Space and on Earth is ideal to deepen the understanding of the formation of the solidification microstructure and of CET. The eutectic and the dendritic structure as well as the CET main features are quantitatively evaluated and compared in both $1 \mathrm{~g}$ and $\mu \mathrm{g}$ conditions to enlighten the influence of gravity.

\section{Experimental}

\subsection{Experiment details}

Within the framework of the CETSOL project, several microgravity experiments $(\mu \mathrm{g})$ and one reference experiment on Earth (1g) have been conducted. In this paper, a comparative study is presented between the only 1g experiment labelled GM (GM for Ground Module) and the corresponding $\mu$ g experiment B1FM5 (B1 for Batch1, FM for Flight Module, and noted as FM hereafter) processed with identical solidification parameters. Both the GM and FM samples here were elaborated using the Low Gradient Furnace (LGF), which was described in details in our previous studies [37]. The LGF is a Bridgman-type furnace, which consists of two heating zones separated by an adiabatic region. The cold zone and the hot zone are constituted of three (H1-H3 in Fig.1) and four (H4-H7 in Fig.1) separated heating elements, respectively. The temperature of each heating element can be adjusted independently during the solidification to achieve the required temperature profile along the solidification direction. For the ground experiment, the LGF pulling direction is vertical upward along the fixed mounted sample, opposite to the gravity direction, leading to an upward solidification direction.

The sample cartridge assembly (SCA) is schematized in Fig.1. The alloy sample is mounted 
inside a protective $\mathrm{Al}_{2} \mathrm{O}_{3}$ tube crucible with Shapal plugs at both bottom and top ends. Twelve N-type thermocouples (labelled TC1-TC12), spaced by $10 \mathrm{~mm}$, are located in four machined external axial grooves at the outer surface of the crucible to record the temperature evolution profiles along the sample.

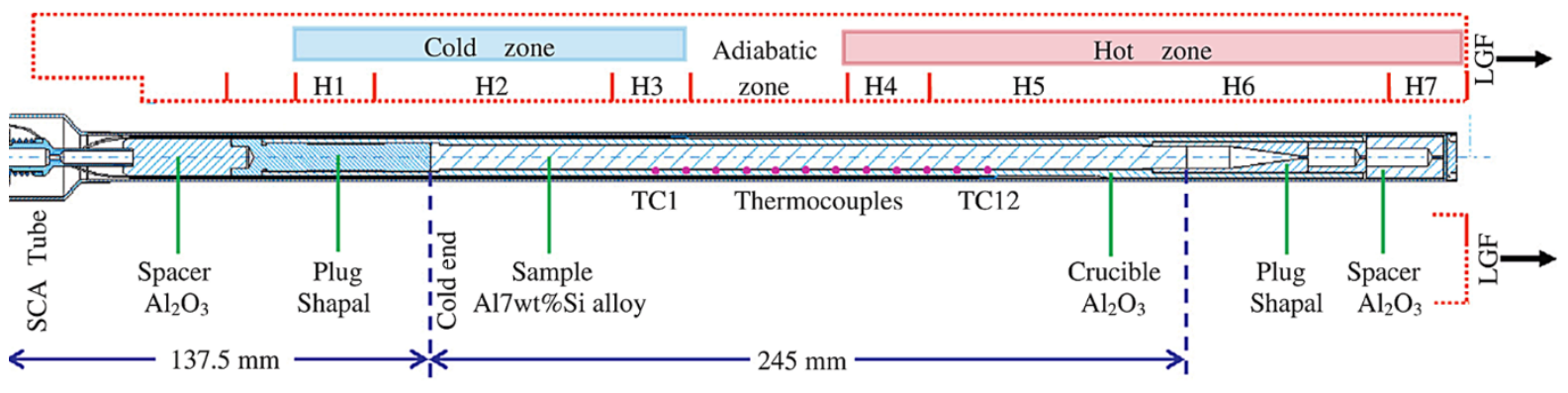

Fig.1. Sketch of a CETSOL Batch 1 cartridge MSL-SCA integrated in the MSL-LGF furnace showing the situation at the beginning of the solidification phase.

Table 1. Control parameters for samples solidified under gravity (1g) and microgravity $(\mu \mathrm{g})$ : $\mathrm{v}_{\mathrm{n}}$ is the furnace pulling velocity, $\mathrm{z}_{\mathrm{n}}$ the solidification length under $\mathrm{v}_{\mathrm{n}}$ in stage $\mathrm{n}, \mathrm{G}$ the initial temperature gradient und $\mathrm{R}$ the cooling rate in Stage II.

\begin{tabular}{ccccccccc}
\hline & & \multicolumn{3}{c}{ Stage I } & & Stage II & & Stage III \\
Sample & Gravity & $\begin{array}{c}\text { Initial G, } \\
\mathrm{K} / \mathrm{mm}\end{array}$ & $\mathrm{v}$, $\mathrm{mm} / \mathrm{s}$ & $\mathrm{z}_{1}, \mathrm{~mm}$ & $\mathrm{v}_{2}, \mathrm{~mm} / \mathrm{s}$ & $\mathrm{z}_{2}, \mathrm{~mm}$ & $\mathrm{R}, \mathrm{K} / \mathrm{s}$ & $\mathrm{v}_{3}, \mathrm{~mm} / \mathrm{s}$ \\
\hline $\mathrm{GM} / \mathrm{FM}$ & $1 \mathrm{~g} / \mathrm{\mu g}$ & 0.9 & 0.01 & 20 & 0.01 & 20 & 0.067 & 3 \\
\hline
\end{tabular}

Both grain refined Al-7 wt.\% Si (AlSi7) samples are prepared from a same batch provided by Hydro Aluminum GmbH. 0.5 wt\% of master alloy AlTi5B was added to the sample for grain refinement. Samples have a cylindrical shape with a diameter of $8 \mathrm{~mm}$ and a length of 245 mm. The main solidification parameters, identical for both samples, are summarized in Table 1.

The solidification procedure consists of three successive stages: 
- Stage I: The initial temperature gradient $(\mathrm{G})$ is about $0.9 \mathrm{~K} / \mathrm{mm}$. The solidification is initiated by the furnace motion at a low pulling velocity $\left(\mathrm{v}_{1}=0.01 \mathrm{~mm} / \mathrm{s}\right)$ for $20 \mathrm{~mm}$.

- Stage II: The second stage is triggered by a cooling down of the hot zone at a cooling rate of $0.067 \mathrm{~K} / \mathrm{s}$, which yields to a continuous decrease of the temperature gradient. The furnace motion length is $20 \mathrm{~mm}$ for this stage and the pulling rate is identical to the stage $\mathrm{I}\left(\mathrm{v}_{1}=0.01\right.$ $\mathrm{mm} / \mathrm{s})$.

- Stage III: A furnace pulling at a velocity of $3 \mathrm{~mm} / \mathrm{s}$ is applied to complete the solidification. During this final stage, the temperature gradient and the cooling rates are no longer controlled, but the temperature profiles are still recorded, which enable us to determine these two important experimental parameters.

\subsection{Microstructure characterization}

After solidification, both samples are cut in the same manner into transverse and longitudinal sections and prepared for metallographic analysis, the sketch of the cutting sections are shown in Fig.2. Longitudinal sections are cut close to the centerline. The samples were mechanically polished with diamond suspension to identify the dendritic microstructure. Then, electrolytic etching was performed to distinguish dendrites with different crystallographic orientations in different colors using an optical polarized light microscope (OM) and thereby to reveal the grain structure.

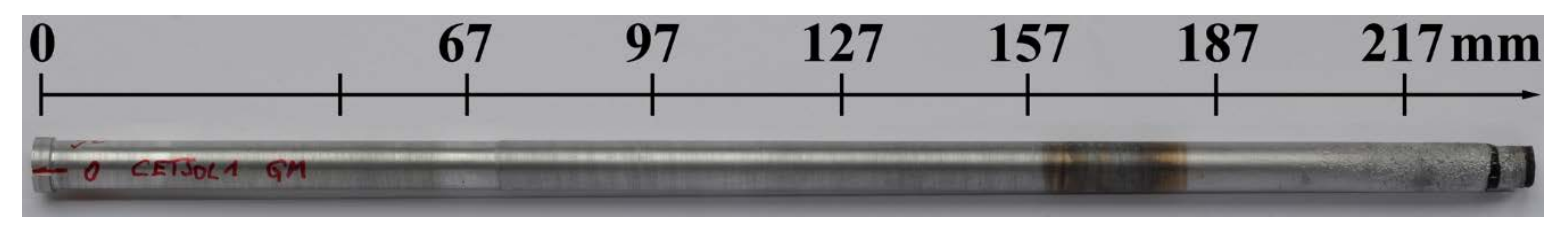

Fig.2. Photograph of the processed GM sample with identification of cross-section positions.

The OM images of the longitudinal sections located at the level of the transition from the stage I to the stage II for both the GM and FM samples are first segmented into binary images 
using a threshold to separate the two phases: dendrite and eutectic phase. Based on those binary images, the eutectic percentage (E\%) maps are determined to display the distribution of the eutectic phase, using a box-averaging method with a box size of $0.875 \mathrm{~mm}$ in length, along the sample axis direction, and $0.656 \mathrm{~mm}$ in width, along the sample diameter direction. The size of the averaging box is indicated in Fig. 4 in comparison to the sample size. From the binary images revealing dendrites and eutectic, a linear intercept method is applied to determine the dendrite arm spacing (DAS) [37]. For each data point of DAS, thousand lines are randomly generated in each measuring box to increase the result statistics and reliability. It is worth to mention here that this measured DAS is not equal to the primary or secondary dendrite arm spacing but is a useful average characteristic to display the scale of the dendritic structure as described before [37, 41]. Moreover, DAS and E\% profiles along the solidification direction, i.e. along the main cylindrical sample axis are determined by averaging within boxes of $0.875 \mathrm{~mm}$ in length and including the whole sample diameter in width.

\section{Results}

\subsection{Analysis of the processing parameters}

The recorded temperature profiles during the solidification for both samples are shown in Fig.3a and b, respectively. Based on the temperature profiles, the temperature gradient ahead of the liquidus isotherm $\left(T_{L}=891 \mathrm{~K}\right.$ for $\left.\mathrm{Al}-7 \mathrm{wt} . \% \mathrm{Si}\right) \mathrm{G}_{\mathrm{L}}$ and the velocity of the liquidus isotherm $v_{\mathrm{L}}$ of both samples are calculated, as shown in Fig.3c and d, respectively. Based on the linear interpolation method, the temperature gradient ahead of the liquidus isotherm is calculated at the time when the liquidus isotherm reaches a thermocouple $T_{N}$, by the temperature difference and the known distance $10 \mathrm{~mm}$ between $\mathrm{T}_{\mathrm{N}}$ and its neighboring thermocouple $\mathrm{T}_{\mathrm{N}+1}$. Then, the velocity of the liquidus isotherm can be deduced by the liquidus 
isotherm positions at this instant and next time-step. The temperature gradient and velocity of the liquidus isotherm are calculated for each stage and are gathered in Table 2 as average value for stage I and as Minimum/Maximum values in stage II. The procedure, described in details in our previous work [37], is similar to the method used by Gandin [42].

The transition position between stages, as indicated by the vertical blue dashed lines in Fig.3, are also deduced from the cooling curves delimited by the transition time at which the furnace started to move for every stage. The calculation details of these positions were explained in our previous work [37]. The transition positions between stages I and II are $133.3 \mathrm{~mm}$ and $132.1 \mathrm{~mm}$ for the GM and the FM sample, respectively. The transition positions between stages II and III cannot be determined because the temperatures (below $867 \mathrm{~K}$ ) at the level of the highest thermocouple TC12 (position of $182.5 \mathrm{~mm}$ ) at the instant of the transition from stage II to III are already much lower than the liquidus temperature (891 K) as indicated from the temperature records.
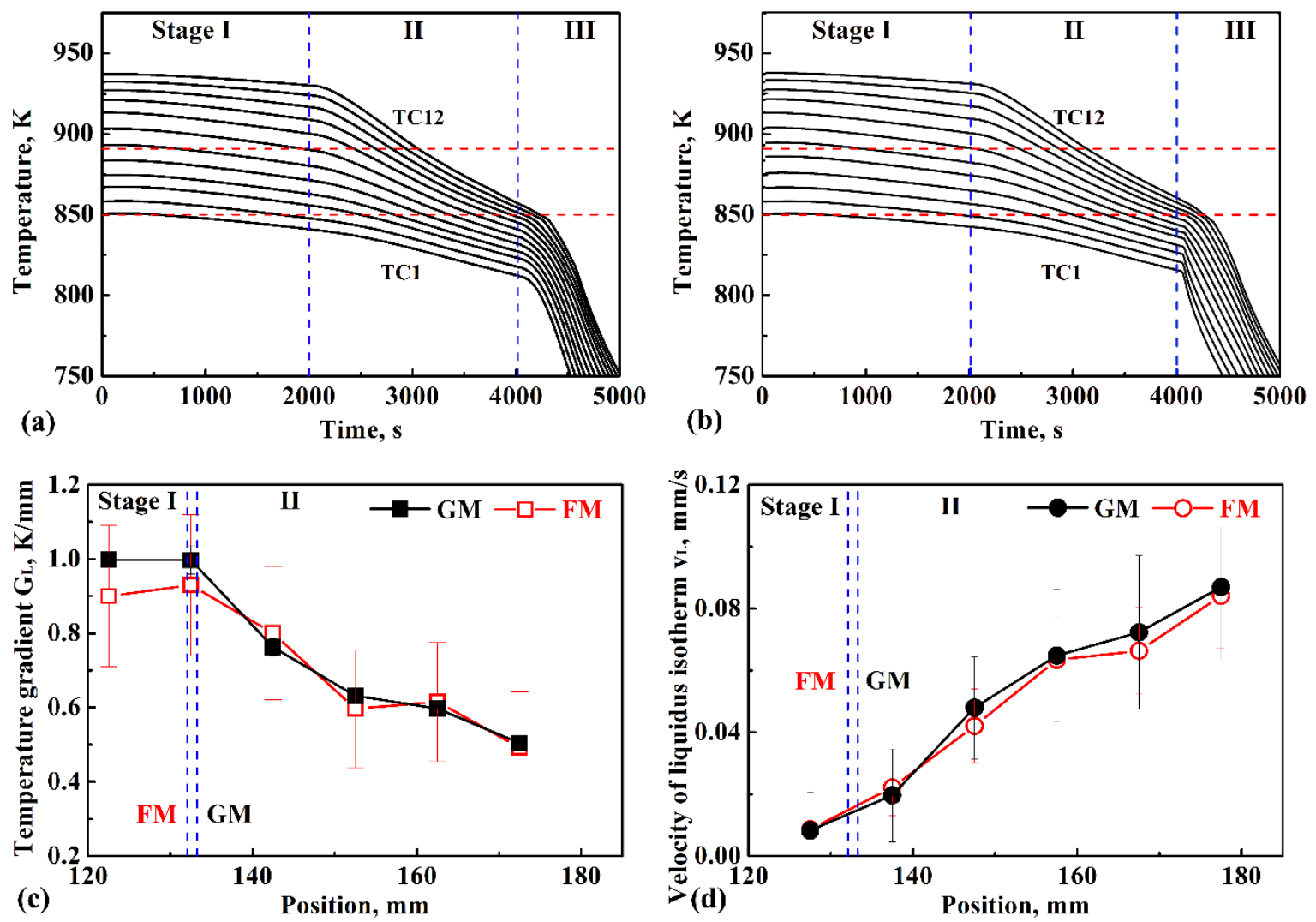

Fig.3. (a) and (b) Temperature curves recorded by the thermocouples during the experiments 
for the GM and FM samples, respectively. Liquidus and eutectic isotherms $\left(T_{L}=891 \mathrm{~K}\right.$ and $\mathrm{T}_{\mathrm{E}}=850 \mathrm{~K}$ ) are indicated with red horizontal dashed lines. The boundaries between the different solidification stages are indicated with blue vertical dashed lines. (c) The calculated temperature gradient ahead of the liquidus isotherm $G_{L}$ and (d) the calculated average liquidus isotherm velocity $v_{L}$ between two thermocouples of both GM and FM. The boundaries between stages I and II are indicated with blue vertical dashed lines.

Table 2. Processing parameters and average values of both the eutectic percentage (E\%) and the dendrite arm spacing (DAS) in each stage of the GM and FM samples. In stage I, the calculated values of $\mathrm{G}_{\mathrm{L}}$ are constant and only one value of $\mathrm{v}_{\mathrm{L}}$ is obtained, whereas in stage II, for which an evolution is observed, minimum and maximum values are given.

\begin{tabular}{cccccc}
\hline Sample & Stage & $\mathrm{G}_{\mathrm{L}}, \mathrm{K} / \mathrm{mm}$ & $\mathrm{v}_{\mathrm{L}}, \mathrm{mm} / \mathrm{s}$ & $\mathrm{E}, \%$ & DAS, $\mu \mathrm{m}$ \\
\hline \multirow{2}{*}{ GM } & I & 1.0 & 0.01 & 44 & 131 \\
& Initial part of II & From 1 to 0.6 & From 0.01 to 0.06 & 45 & 117 \\
\multirow{2}{*}{ FM } & I & 0.9 & 0.01 & 53 & 134 \\
& Initial part of II & From 0.9 to 0.6 & From 0.01 to 0.06 & 48 & 95 \\
\hline
\end{tabular}

The curves in Fig.3 show similar temperature profiles and also $G_{L}$ and $v_{L}$ profiles of $G M$ and FM for the entire calculated range, indicating that the influence of the gravity on the detected thermal field during the solidification process is not significant here. The calculated values of $\mathrm{G}_{\mathrm{L}}$ are almost constant in stage I, whereas the calculated values of $\mathrm{G}_{\mathrm{L}}$ gradually decrease and the calculated $\mathrm{v}_{\mathrm{L}}$ increases in stage II, as can be seen in Fig.3. Table 2 gathers the main processing parameters in both stages. It should be mentioned that only the first $25 \mathrm{~mm}$ are considered in the analysis of $\mathrm{G}_{\mathrm{L}}$ and $\mathrm{v}_{\mathrm{L}}$ in stage II for comparison to the microstructure shown in Fig.4. The comparison is discussed in more details in Section 4. Table 2 summarizes the 
initial and final values of $G_{L}$ and $v_{L}$ within this interval and includes the average values of the microstructure analysis. The length of the mushy zone $\left(\mathrm{L}_{\mathrm{Mz}}\right)$ during the solidification process, defined by the distance between the liquidus and the eutectic isotherms $\left(T_{L}=891 \mathrm{~K}\right.$ and $\mathrm{T}_{\mathrm{E}}=850 \mathrm{~K}$ ), was also calculated to estimate the transition position from stage II to III. The average value of the mushy zone length is estimated at about $50 \mathrm{~mm}$ in stage I and gradually increases in stage II for both the GM and FM samples, which is expected due to the decreasing $G_{L}$ in stage II.

\subsection{Analysis of the microstructure}

Microstructures of the longitudinal sections corresponding to the transition between stage I and stage II are displayed for both samples in Fig.4a1 and 4b1. Different electrolytical etching methods are applied resulting in different color maps. The bottoms of Fig.4a1 and 4b1 correspond to the start position of stage I. The blank regions between two sections for both samples represent the material loss during the sample cutting and the transverse section micrograph preparation. The solidification stages and the corresponding furnace pulling velocities are indicated on the left side of the figure, based on the transition positions from stages I to II determined in Fig.3.

As shown in Fig.4a1 and 4b1, a columnar structure is revealed in stage I for both samples. Close to the transition position from the stage I to the stage II, the growth of the columnar grains issued from the initial dendrites zone are blocked by other grains indicated by the different colors and stem growth directions for both samples as highlighted by the white dash lines in Fig.4a1 and 4b1. For the FM sample, according to previous studies [37, 43], this position defines the CET inception (i.e. end of the fully columnar growth) and is noted as $\mathrm{CET}_{\min }$ in Fig.4b1, as indicated by smaller and equiaxed dendrite grains after this position. The CET could be recognized as progressive mode when considering the elongation factor (EF) of the grains after $\mathrm{CET}_{\min }$ [37]. In such case of progressive CET, an intermediate region 
with elongated equiaxed grains $(\mathrm{EF}>2)$ exists between $\mathrm{CET}_{\min }$ and the fully equiaxed region limit defined as the position for which the average grain elongation is lower than two, according to Hunt's criterion. However, for the GM sample, the new nucleated grains after this position are still columnar as shown in Fig.4a1, although the initial columnar dendrites grains from stage I are effectively blocked. The $\mathrm{CET}_{\min }$ for the GM sample locates at the position of about $150 \mathrm{~mm}$ as shown by the yellow dash line in Fig.4a1, which is far from the transition position from stage I to II, indicating a much more progressive CET in the GM sample than in the FM sample.

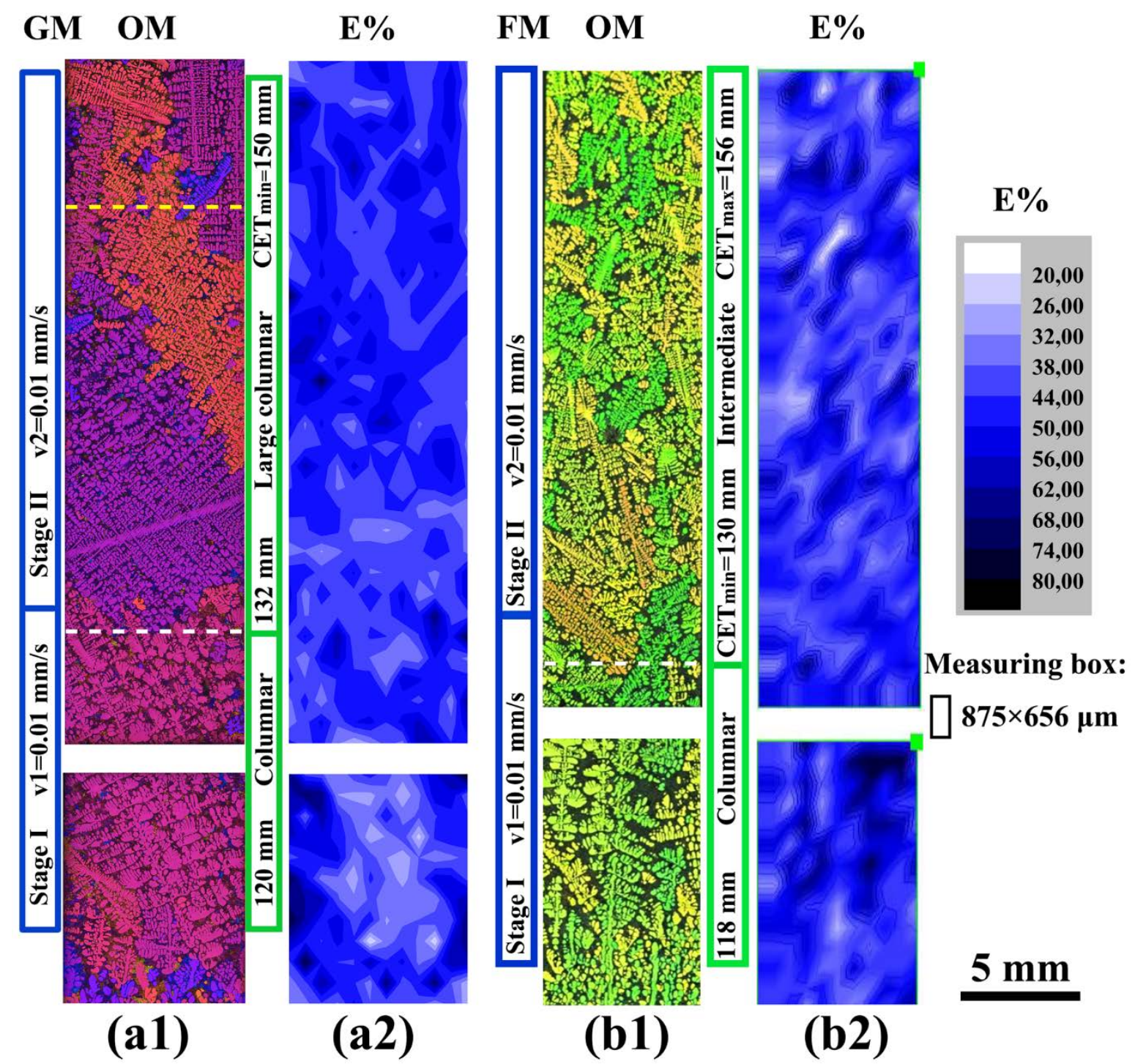

Fig.4. Microstructure along longitudinal sections in the region of the transition from stage I to stage II for: (a1) the GM sample and (b1) the FM sample. Corresponding eutectic percentage 
distribution maps (a2 and b2) for both samples. The white dashed lines represent the highest position of the columnar grains issued from the initial dendritic zone. The yellow dashed line represents the position of $\mathrm{CET}_{\min }$ in the GM sample.

The eutectic percentage (E\%) maps calculated from the micrographs of the same regions are shown in Fig.4a2 and 4b2. The shade of the blue color indicates the magnitude of the eutectic percentage as labelled in the right-side scale. The eutectic forms after the dendritic phase and is a consequence of the solute rejection from the dendrite and accumulation in the interdendritic regions. It can be seen that in stage I for both samples, a few large eutectic regions are found, illustrating an inhomogeneous distribution of the eutectic percentage. In stage II, no more large eutectic zones are found and the eutectic distribution is more homogeneous as expected for an equiaxed grain structure. The difference of the eutectic distribution between the GM and the FM sample is not significant and should mostly be related to the different dendrite grain sizes in the measured regions.

In order to better understand the role of the solidification parameters on the microstructure, the longitudinal profiles of the eutectic percentage (E\%) and of the dendrite arm spacing (DAS) are plotted in Fig.5.
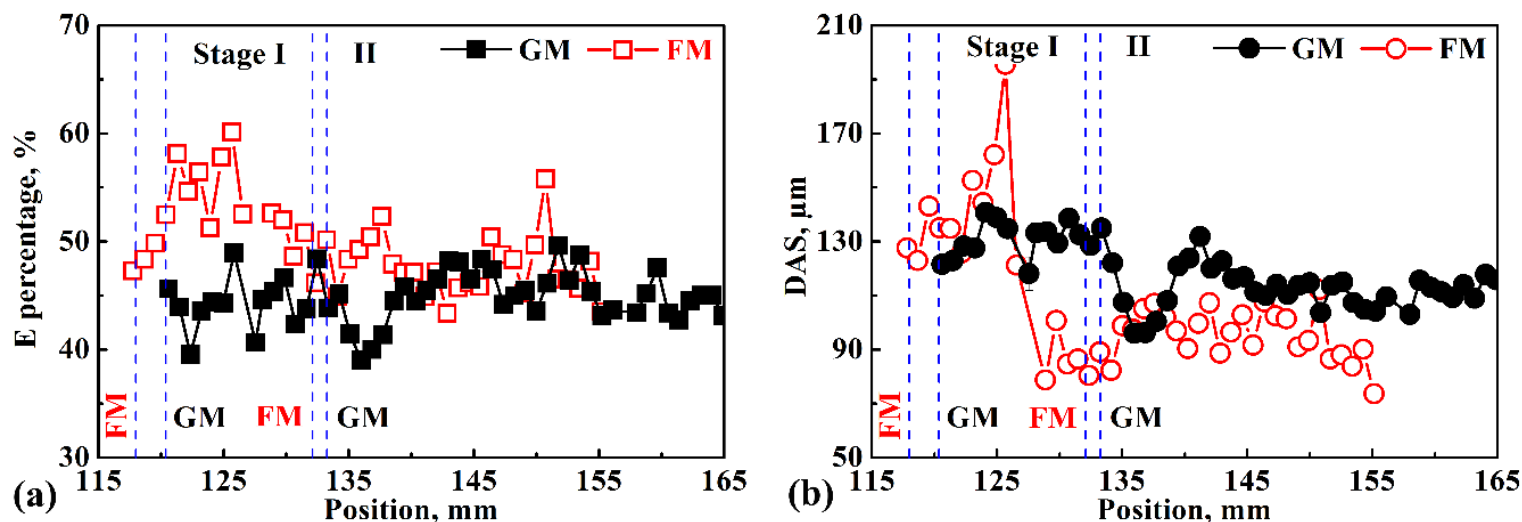

Fig.5. (a) Mean eutectic percentage and (b) mean DAS vs. position along the longitudinal direction of both the GM and the FM samples. The boundaries between different 
solidification stages are indicated with blue vertical dashed lines.

The transition positions between the different solidification stages are indicated with blue vertical dashed lines with the corresponding samples, similar to Fig.3. Furthermore, the average values of E\% and DAS in the stage I and initial part of stage II, according to the calculated values of $\mathrm{G}_{\mathrm{L}}$ and $\mathrm{v}_{\mathrm{L}}$, are gathered in Table 2. The results in Fig.5 and Table 2 suggest that, in the GM sample, the $\mathrm{E} \%$ is constant from the stage I to the stage II (black squares in Fig5a), whereas the DAS slightly decreases (black dots in Fig.5b). However, both the E\% and DAS decrease from the stage I to the stage II in the FM sample (red symbols in Fig.5a and Fig.5b). Moreover, the average E\% is higher in the FM sample compared to the GM sample in the stage I whereas the values are comparable in the stage II. Besides, the average DAS values are comparable for both samples in the stage I (131 $\mu \mathrm{m}$ and $134 \mu \mathrm{m})$ whereas the average DAS is much lower in the FM sample $(95 \mu \mathrm{m})$ compared to the GM sample $(117 \mu \mathrm{m})$ in the stage II. This difference is ascribed to the gravity which will be discussed later. 

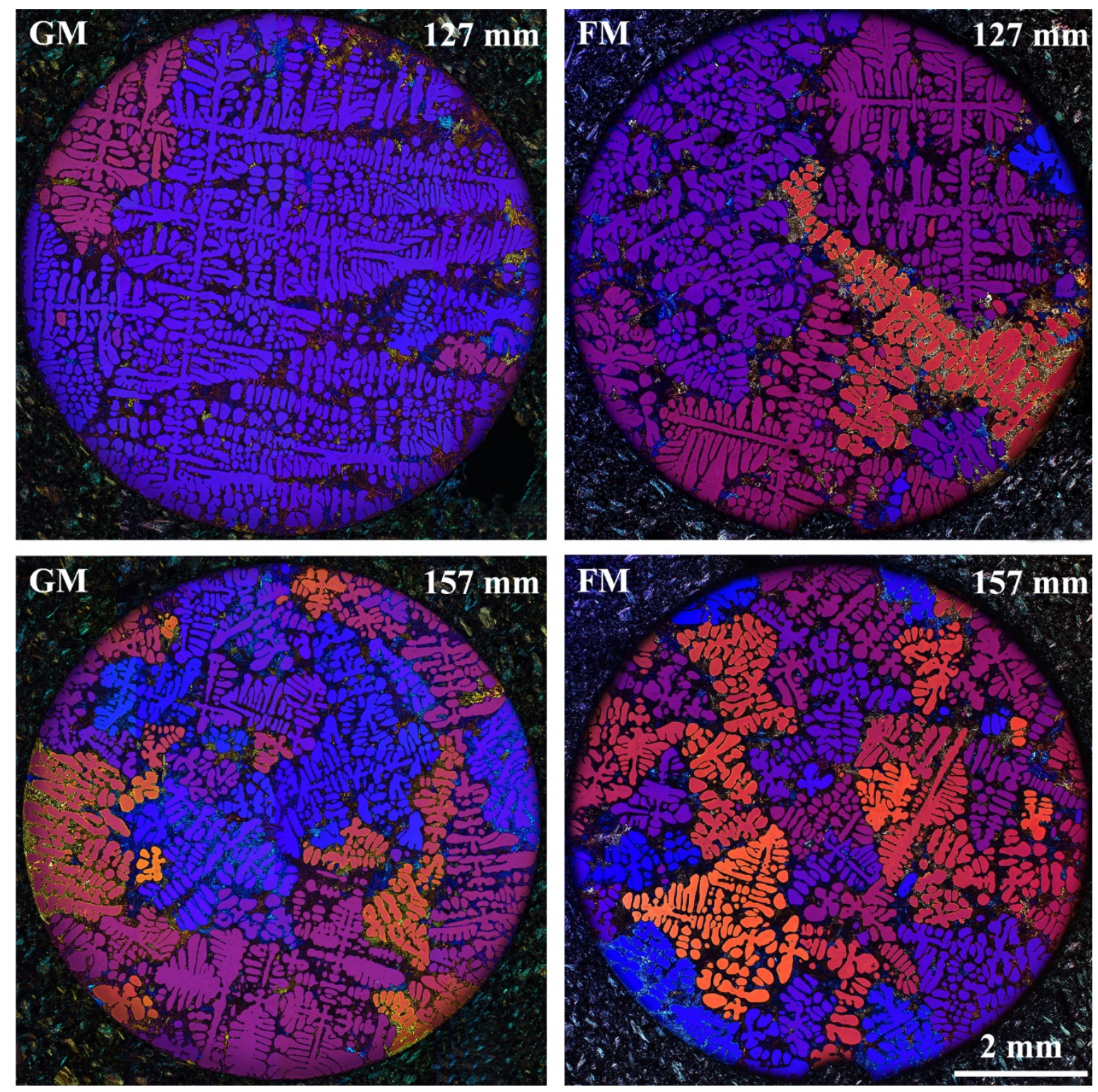

Fig.6. Microstructure of the transverse sections at two different solidification positions for GM and FM samples. According to Fig.4, the sections at $127 \mathrm{~mm}$ and $157 \mathrm{~mm}$ are in stages I and II, respectively.

It was mentioned in Section 2.2 that the DAS shown in Fig.5 is only an average characteristic of the dendritic structure. However, the microstructure of the transverse section could be used to measure the average grain size of the dendritic structures [44] as

$$
\lambda=\sqrt{A / n}
$$

where $\lambda$ is the average grain size, $\mathrm{A}$ is the analyzed area, and $\mathrm{n}$ is the number of grains in this area. Microstructures of the transverse sections corresponding to the positions shown in Fig.2 
are displayed for both samples in Fig.6. According to Fig.4, the sections at $127 \mathrm{~mm}$ and 157 mm are in the stages I and II, respectively. Therefore, these sections could be used to estimate the average grain size in the stage I and II, respectively. By counting the number of the grains in the sections shown in Fig.6, the $\lambda$ values in the stage I are $4.1 \mathrm{~mm}$ and $2.1 \mathrm{~mm}$ for $\mathrm{GM}$ and FM, respectively, and in the stage II are $1.5 \mathrm{~mm}$ and $1.3 \mathrm{~mm}$ for GM and FM, respectively. This shows that in both cases (GM and FM), lower $\lambda$ values were obtained due to the higher solidification velocity in the stage II, as shown in Fig.3 and Table 2. Specifically, larger $\lambda$ values in the GM sample compared to the FM sample in both the stages I and II could be observed, especially in the stage I under a lower solidification velocity.-

\subsection{Particular observation of a long columnar dendrite in stage II of the GM sample}

Microstructures of the longitudinal sections of the GM sample are displayed in Fig.7. It can be seen that the two large dendritic grains in the start region of stage II, almost occupy the whole sample width as shown in Fig.7a and Fig.4 above. At higher solidification length, the grain size decreases, with a more equiaxed characteristic in the following solidification steps. These observations are related to the increasing growth velocity and decreasing temperature gradient as mentioned in Section 3.1. Nevertheless, a long dendrite growing close to the sample axis, i.e. the direction parallel to the temperature gradient, is observed in the same region, as indicated by the white arrows in Fig.7a. The maximum length of this dendrite is up to $62 \mathrm{~mm}$. 

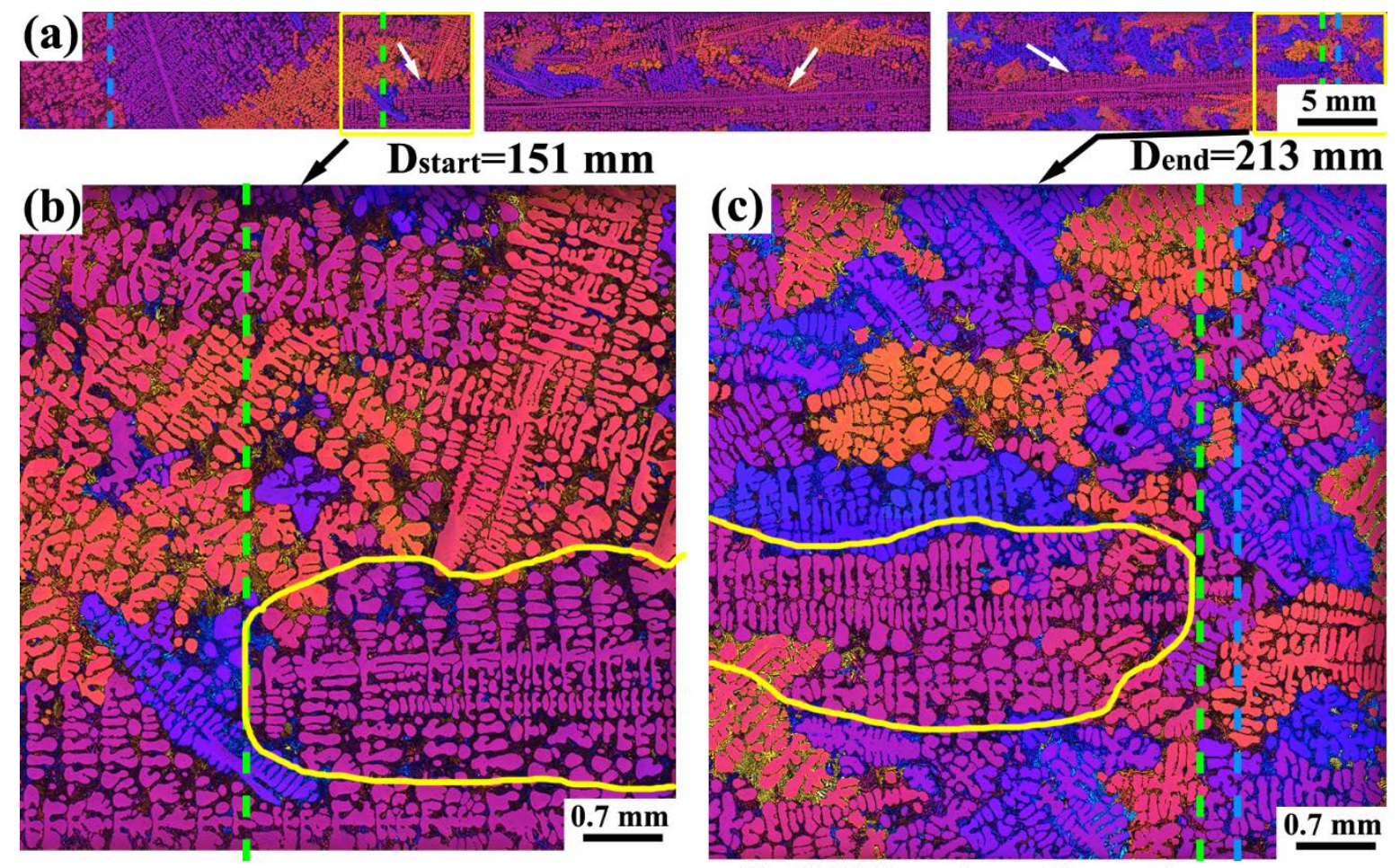

\section{Solidification direction}

Fig.7. Microstructure along longitudinal sections in the GM sample: (a) Section identical to the upper part of Fig.4a1 on which zoomed sections in the bottom are indicated by yellow boxes, (b) the start region of the large dendrite, (c) the end region of the large dendrite. The green dashed lines show the start and end of the long dendrite. The blue dashed lines in (a) and (c) show the transition position from the stage I to II and the estimated transition position from the stage II to III, respectively.

Fig.7b and Fig.7c show the zoomed images of the largest dendrite outlined in yellow. For this dendrite, the secondary arms are almost perpendicular to the primary trunk, which indicates that the primary trunk growth direction of this dendrite corresponds to the cutting section displayed in Fig.7, the $<100>$ direction being the prior crystal orientation of $\alpha$-Al dendrite growth in this alloy. Thereby, the growth direction of this dendrite is almost parallel to the thermal gradient and anti-parallel to gravity i.e. vertical. The start position of this longest dendrite is just located in front of the two big dendrites in the beginning of the stage II. 
Finally, the growth of this dendrite is blocked by numerous and finer dendritic grains in the region close to the transition position from the stage II to III, which was estimated by the length of the mushy zone.

\section{Discussion}

\subsection{Effect of the thermal conditions (G, v) on the microstructure and CET}

The growth velocity of the dendrite tips is approximated by the liquidus isotherm velocity $\mathrm{V}_{\mathrm{L}}$ during the solidification. In stage I, large solute-enriched liquid pockets in the interdendritic region form and later transform into large eutectic zones because of the large size of the dendrites. These large dendrites are due to the low growth velocity in the stage I, as shown in Fig.3b. In the stage II, the continuous increase of the growth velocity triggers the dendritic branching and consequently decreases the typical size of dendrite structure. Accordingly, a more homogeneous eutectic distribution is observed in the stage II compared to the stage I. Moreover, in a refined alloy as the one used in the experiments, the origin of equiaxed grains is dominated by the nucleation on added refining particles [45, 46]. The enhanced undercooling in front of the columnar dendrites due to growth velocity increase results in an increasing amount of nucleation of equiaxed grains on refiners ahead of the columnar front. These newly nucleated grains ultimately block the initial columnar grains, leading to the inception of CET in stage II for both the GM and FM samples and defining the position $\mathrm{CET}_{\min }$. The progressive CET observed for both samples means that the final applied temperature gradient and pulling rate are located in the solidification parameters range of columnar and equiaxed mixed region [2, 37, 47].

\subsection{Effect of the gravity on the microstructure}

\subsubsection{The natural convection flow and its effect on CET}


The significant differences of the solidification microstructure observed between the GM and the FM sample indicate that the gravity significantly affects the solidification process, which also has been reported previously $[33,48,49]$. According to calculated $\mathrm{G}_{\mathrm{L}}$ and $\mathrm{v}_{\mathrm{L}}$, as shown in Fig.3 and Table 2, no significant variation of the thermal field is observed between the two samples. Therefore, the distinction of the microstructure and CET features between the GM and the FM sample can only be attributed to the different gravity conditions between the two experiments.

It has to be discussed, whether the amount or distribution of the grain refiner (GR) we used in this study can be different in the GM and FM samples. Before starting the solidification stage I, a temperature adjustment and thermal homogenization phase of about 110 min existed in both experiments. In this initial state about $2 / 3$ of the samples lengths was melted and a similar and nearly stable distribution and amount of the active GR would be expected both in GM and FM samples [50]. As shown in the study of Reinhart et al. [51], the amount and distribution of the active GR always remained similar even after several times of remelting of the aluminum alloy on Earth, which indicated that the sedimentation of the GR could be neglected during the solidification under the $1 \mathrm{~g}$ condition. Therefore, also the amount and distribution of the active GR will be considered the same for the GM and FM samples.

On Earth, natural convection or fluid flow is induced by instable density gradients from the constitutional and thermal gradients in the liquid phase. Then, natural convection in general changes the thermal and solutal conditions ahead of the dendrite front and also in the mushy zone [3, 9]. Based on previous results [15, 19, 26, 50], from both experiments and simulations, the qualitative liquid flow patterns induced by the gravity in the mushy zone and ahead of the dendrite front during the solidification can be estimated in this experiment. In practice, solutal convection dominates in the case of metallic alloys owing to their large Lewis number defined as the ratio of the thermal diffusivity to the solutal one $\left(\right.$ Le $\left.=D_{t h} / D\right)$, 
typically of the order of $10^{3}$ to $10^{4}$.

Generally speaking, in presence of gravity and depending on the alloy (partition coefficient $k$ and respective densities of alloy elements), the convection flow is different in the two regions illustrated in Fig.8 [15, 26, 50]: within the mushy layer (generally considered as a porous medium) and in the region ahead of the mush/liquid interface. In the latter case, the characteristic length scale may vary from several times the solutal length $\mathrm{D} / \mathrm{V}$ (V being the solidification velocity) up to the sample size far from the S/L interface.

Moreover, convection liquid flow can exist in the interdendritic region due to the solutal effects (rejection of solute during the phase transition) and volume shrinkage. It is worth mentioning that the former convection is gravity-dependent, whereas the latter effect is not gravity-dependent. Accordingly, shrinkage flow becomes dominant in the mushy zone and in the close vicinity of the columnar front in microgravity experiments as recently revealed by in situ observation during equiaxed growth in isothermal conditions [51], as well as during directional solidification [52]. In the case of $\mathrm{Al}-7 \mathrm{wt} \% \mathrm{Si}$, it is expected that the solutal induced flow has a rather low velocity because of the weak density difference between $\mathrm{Al}$ and Si. But the convection induced by the radial temperature gradient also existed, which would enhance the liquid flow [3, 26]. As mentioned by Jung [53], under the solidification parameter $\mathrm{G}=0.5 \mathrm{~K} / \mathrm{mm}$ and $\mathrm{v}=0.002 \mathrm{~mm} / \mathrm{s}$, the maximum convection velocity for Al- $7 \mathrm{wt} \% \mathrm{Si}$ (2.3 $\mu \mathrm{m} / \mathrm{s})$ was much higher than that for Al- $3.5 \mathrm{wt} \% \mathrm{Ni}(0.9 \mu \mathrm{m} / \mathrm{s})$, even though the density difference between $\mathrm{Al}$ and $\mathrm{Ni}$ is much larger. In the zone ahead of the tip of the large dendrite, the convection liquid flow pattern is drawn in black dash cyclo-streamlines, labelled (1), in Fig.8, and can extend from the solidification front to far away in the liquid region. As a possible scenario, the flow directions are downward in the center and upward at the edges, according to the simulation results reported by Zhou et al. [26]. Newly nucleated equiaxed grains are present in the undercooled zone delimitated by the dendrite tips and the liquidus 
temperature isotherm $\left(T_{L}\right)$. The liquid flow (1) is assumed to be stronger than the liquid flow inside the mushy zone because of the decreasing permeability when going down towards the eutectic isotherm. Besides, there is a liquid flow in the close vicinity of the large dendrite tip, indicated by the dashed red box in Fig.8, as reported respectively by Zhou [26] and Karagadde [50]. Indeed, minor flow rolls, at the scale of the primary spacing, were described by Karagadde in this region and adhering to the dendrites, both between two dendrites and in front of the tip of one single dendrite [50].

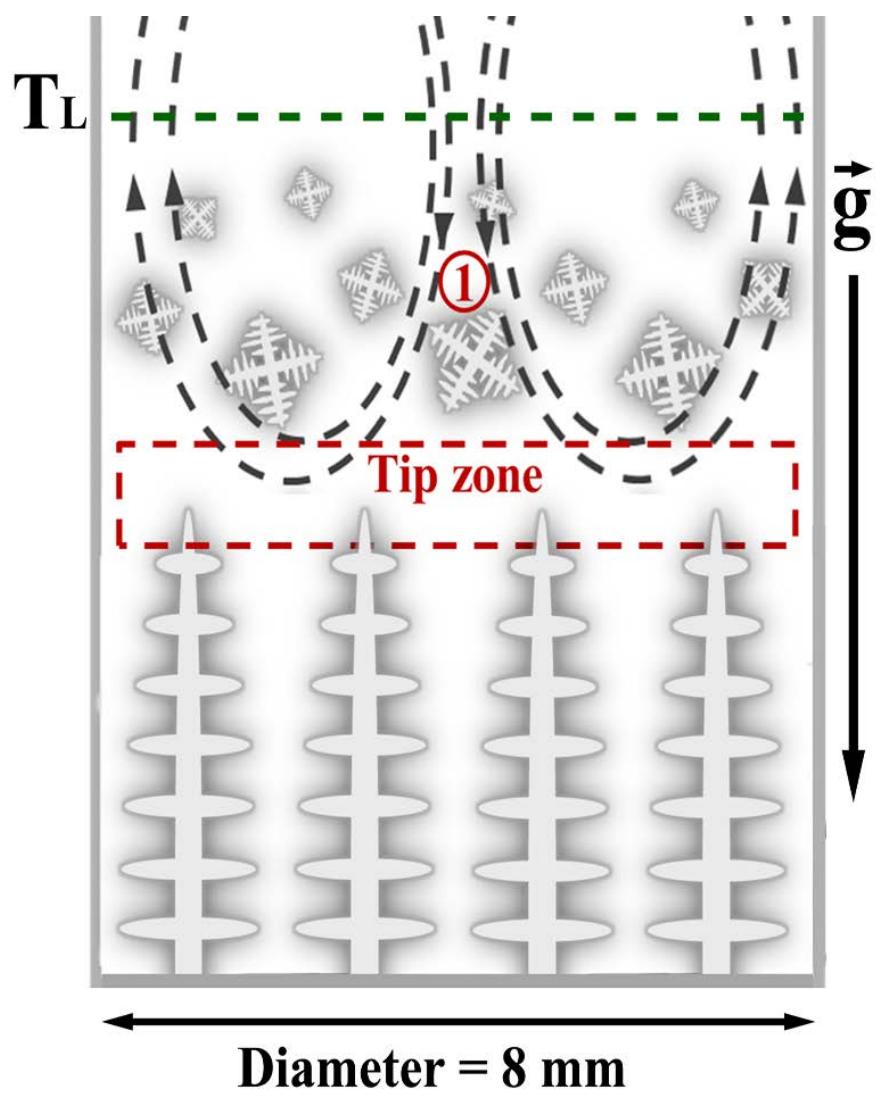

Fig.8. Schematic patterns of the liquid flow ahead of the dendrite front due to gravity during upward solidification (1). The upper green dash line indicates the liquidus isotherm position $\left(\mathrm{T}_{\mathrm{L}}\right)$

In FM sample under $\mu$ g condition, the new nucleated grains and solute rejected from the equiaxed and columnar growing dendrites are not submitted to flow and sedimentation 
phenomena so that equiaxed grains accumulate in the undercooled region and solute builds up triggering CET. On the contrary, in the GM sample, the bulk convective flow ((1) in Fig.8) carries part of both the new grains and of the solute away from the columnar tip zone towards the upper liquid region where the temperature is higher and the Si concentration is lower. Consequently, the transported equiaxed grains are most likely remelted as in situ observed by Nguyen-Thi et al. during the solidification of Al-20wt.\% Cu alloy [54]. It is worth noting that the transport of the dendritic grains far into the liquid where they are remelted inhibits or delays the columnar-to-equiaxed transition. Additionally, the lower extent flows in the tip region can participate to the removal of new grains and of the solute away from the columnar tip zone. In summary, due to gravity effects, the blocking of the columnar front is alleviated or diminished and the growth of the columnar dendrite and of the remaining equiaxed grains is promoted, leading to a more progressive CET and much larger dendrites in the GM sample.

\subsubsection{The long dendrite growth in GM}

As shown in Fig.4a1 and Fig.7b, several dendrite grains nucleate and grow in the GM sample after $\mathrm{CET}_{\min }$. During dendrite growth, the growth direction of the primary trunk is controlled by the initial grain orientation when no seed is used, by the direction of the temperature gradient at low velocity and by crystallographic effects at high velocity. In some cases, the dendrite primary trunk is well aligned with the temperature gradient direction as for example the long dendrite in Fig.7b in the GM sample. Fig.9 illustrates the dendrite tip motion of two dendrites with different misorientations relatively to the temperature gradient direction during upward solidification: (1) $0^{\circ}$ and (2) $\theta$.

The growth competition of these two dendrites could be explained by the classical model proposed by Walton and Chalmers [55-57]. During the steady-state dendrite growth, grains at the solidification front should grow at the same velocity in the direction of the temperature 
gradient, so that $\mathrm{v}_{1}=\mathrm{v}_{2}{ }^{\prime}$ for the two dendrites in Fig.9. Consequently, the tip growth velocity of the dendrite (2) would be higher than that of the dendrite (1), i.e. $\mathrm{v}_{2}>\mathrm{v}_{1}$. Since the tip growth velocity is linked to the undercooling [58-60], the undercooling is higher at the level of the tip of the dendrite (2) compared to the dendrite (1): $\Delta \mathrm{T}_{2}>\Delta \mathrm{T}_{1}$. Therefore, the tip of the dendrite (2) lags behind the one of the dendrite (1). Thus, as the one observed in Fig.7, the growth of the dendrites aligned with the temperature gradient is expected to be favored in the growth competition process. The growth of this particular dendrite in Fig.7 is stopped by equiaxed grains close to the transition position from the stage II to the stage III. This is attributed to the blocking effect of the large amount of new nucleated grains due to the increase in pulling velocity and cooling rate in the stage III.

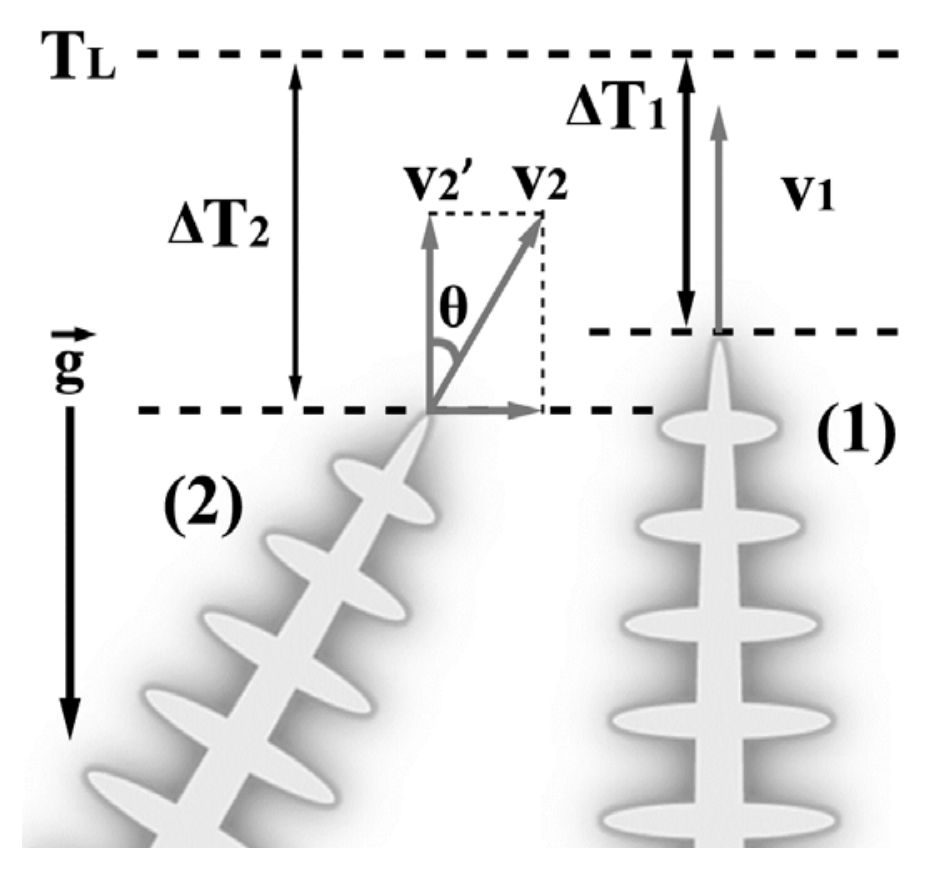

Fig.9. Schematic tip growth velocity of two dendrites with different orientations relatively to the temperature gradient direction: (1) $0^{\circ}$ and (2) $\theta$. The upper dash line indicates the liquidus isotherm position $\left(\mathrm{T}_{\mathrm{L}}\right) \cdot \Delta \mathrm{T}_{1}$ and $\Delta \mathrm{T}_{2}$, and $\mathrm{v}_{1}$ and $\mathrm{v}_{2}$ are the tip undercooling and growth velocities of dendrites (1) and (2), respectively.

\subsubsection{The gravity effect on E\% and DAS}


Additionally, the quantitative microstructure differences between the GM and the FM samples, as mentioned in Section 3.2, are also attributed to the influence of the gravity induced convection, considering the identical solidification parameters. As mentioned in Table 2 and Fig.5, the E\% is lower in the GM sample compared to the FM sample. In the FM sample, the accumulation of the denser solute in the mushy zone results in large E\%. In the GM sample, the lower E\% is the signature of the upward motion of the rejected solute Si due to the intra-dendritic fluid flow, which consequently alleviates the large amount of solute accumulation and leads to smaller eutectic pockets in the GM sample. Due to the bulk liquid flow, the number of equiaxed dendrite grains in the GM sample is lower than in the FM sample, with a much larger grain size, as discussed above. As mentioned in Section 2.2, the DAS measurement takes into account all the primary, secondary and higher order dendrite arm spacing. And the average grain size from transverse sections in the GM sample are larger than in the FM sample. As the DAS measurement includes all spacings (grain size, primary, secondary and eutectic pockets) in a selected zone, a larger DAS value is obtained in the GM sample.

\section{Conclusion}

A ground reference solidification experiment on Earth and a microgravity experiment in the Material Science Laboratory on board the International Space Station were carried out under the same solidification parameters. The influence of the solidification parameters and in particular of the gravity on the microstructure and on the CET have been studied.

(1) The increase of the dendrite growth velocity from the stage I to the stage II leads to finer dendrite structure under both $1 \mathrm{~g}$ and $\mu \mathrm{g}$ conditions. Consequently, a more homogeneous eutectic distribution is achieved in stage II.

(2) The CET is obtained in both samples in a progressive mode. This is directly linked to the 
applied processing conditions, continuous decrease of thermal gradient but at a low furnace pulling velocity, resulting in low undercooling ahead of the columnar dendrite tips. As a consequence, no copious equiaxed nucleation on the refining particles above the columnar front can be expected implying a progressive CET.

(3) The gravity significantly influences the microstructure and the CET because of the existence of the convection liquid flow. Indeed, in the GM, the liquid flow ahead of the solidification front carries both the new grains and the solute away from dendrite tip zone, alleviating or diminishing the blocking effect and promoting the continuous growth of the columnar dendrites. Therefore, the CET is more progressive in the GM sample. Additionally, the $\mathrm{E} \%$ is lower and the DAS is higher in the GM sample than in the FM sample.

(4) Newly nucleated dendrites with the primary trunk aligned with the temperature gradient direction can grow all along the sample until dramatic change of the processing conditions. This is ascribed to their more favorable growth conditions directly linked to their relative orientation to the temperature gradient.

\section{Acknowledgement}

This research work is supported by the European Space Agency under the CETSOL (Columnar to Equiaxed SOLidification processes) ESA MAP project (project No.: AO_99_117 - Contract 14313/01/NL/SH), the French National Space Agency (CNES) and the German Federal Ministry for Economic Affairs and Energy (BMWi/DLR) (project No.: FKZ 50WM1443 and FKZ 50WM1743). The authors acknowledge Hydro Aluminium Rolled Products GmbH for providing the alloys used for the experiments.

\section{References}

[1] J.A. Dantzig, M. Rappaz, Solidification, EFPL Press, 2009. 
[2] H. Jung, N. Mangelinck-Noël, H. Nguyen-Thi, B. Billia, Columnar to equiaxed transition during directional solidification in refined Al-based alloys, J. Alloys Compd., 484 (2009) 739-746. http://dx.doi.org/10.1016/j.jallcom.2009.05.029.

[3] G. Reinhart, C.A. Gandin, N. Mangelinck-Noel, H. Nguyen-Thi, J.E. Spinelli, J. Baruchel, B. Billia, Influence of natural convection during upward directional solidification: A comparison between in situ X-ray radiography and direct simulation of the grain structure, Acta Mater., 61 (2013) 4765-4777. http://dx.doi.org/10.1016/j.actamat.2013.04.067.

[4] J.D. Hunt, Steady state columnar and equiaxed growth of dendrites and eutectic, Mater. Sci. Eng., 65 (1984) 75-83. http://dx.doi.org/10.1016/0025-5416(84)90201-5.

[5] M.A. Martorano, V.B. Biscuola, Predicting the columnar-to-equiaxed transition for a distribution of nucleation undercoolings, Acta Mater., 57 (2009) 607-615. http://dx.doi.org/10.1016/j.actamat.2008.10.001.

[6] C.Y. Wang, C. Beckermann, A unified solute diffusion model for columnar and equiaxed dendritic alloy solidification, Mater. Sci. Eng. A, 171 (1993) 199-211. https://doi.org/10.1016/0921-5093(93)90407-6.

[7] M.A. Martorano, C. Beckermann, C.-A. Gandin, A solutal interaction mechanism for the columnar-to-equiaxed transition in alloy solidification, Metall. Mater. Trans. A, 34 (2003) 1657-1674. https://doi.org/10.1007/s11661-003-0311-x.

[8] G. Reinhart, H. Nguyen-Thi, N. Mangelinck-Noël, T. Schenk, B. Billia, J. Gastaldi, J. Härtwig, J. Baruchel, In-situ observation of transition from columnar to equiaxed growth in Al-3.5 wt\% Ni alloys by synchrotron radiography, Modeling of Casting, Welding and Advanced Solidification Processes, XI (2006) 359-366.

[9] M.D. Dupouy, D. Camel, Effects of gravity on columnar dendritic growth of metallic alloys: flow pattern and mass transfer, J. Cryst. Growth, 183 (1998) 469-489. http://dx.doi.org/10.1016/S0022-0248(97)00415-6. 
[10] R.S. Rerko, H.C. de Groh, C. Beckermann, Effect of melt convection and solid transport on macrosegregation and grain structure in equiaxed Al-Cu alloys, Mater. Sci. Eng., A, 347 (2003) 186-197. https://doi.org/10.1016/S0921-5093(02)00592-0.

[11] H. Nguyen-Thi, G. Reinhart, B. Billia, On the interest of microgravity experimentation for studying convective effects during the directional solidification of metal alloys, C.R. Mec., 345 (2017) 66-77. https://doi.org/10.1016/j.crme.2016.10.007.

[12] A. Bogno, H. Nguyen-Thi, G. Reinhart, B. Billia, J. Baruchel, Growth and interaction of dendritic equiaxed grains: In situ characterization by synchrotron X-ray radiography, Acta Mater., 61 (2013) 1303-1315. http://dx.doi.org/10.1016/j.actamat.2012.11.008.

[13] C.Y. Wang, C. Beckermann, A multiphase solute diffusion model for dendritic alloy solidification, Metall. Trans. A, 24 (1993) 2787-2802. https://doi.org10.1007/bf02659502.

[14] M.H. Burden, D.J. Hebditch, J.D. Hunt, Macroscopic stability of a planar, cellular or dendritic interface during directional freezing, J. Cryst. Growth, 20 (1973) 121-124. https://doi.org/10.1016/0022-0248(73)90125-5.

[15] C.H. Ursolino Gomes, R.H. Lopes Kikuchi, A.d.S. Barros, J.N. Santos da Silva, M.A. Paixao de Sousa da Silva, A.L. Seabra Moreira, O.F. Lima da Rocha, On the Natural Convection in the Columnar to Equiaxed Transition in Directionally Solidified Aluminum-based Binary and Multicomponent Alloys, Materials Research-Ibero-American Journal of Materials, 18 (2015) 1362-1371. http://dx.doi.org/10.1590/1516-1439.036315.

[16] J. Hui, R. Tiwari, X. Wu, S.N. Tewari, R. Trivedi, Primary dendrite distribution and disorder during directional solidification of Pb-Sb alloys, Metall. Mater. Trans. A, 33 (2002) 3499-3510. https://doi.org/10.1007/s11661-002-0337-5.

[17] S. Steinbach, L. Ratke, The influence of fluid flow on the microstructure of directionally solidified AlSi-base alloys, Metall. Mater. Trans. A, 38A (2007) 1388-1394. https://doi.org/10.1007/s11661-007-9162-1. 
[18] J.E. Spinelli, I.L. Ferreira, A. Garcia, Influence of melt convection on the columnar to equiaxed transition and microstructure of downward unsteady-state directionally solidified Sn-Pb alloys, J. Alloys Compd., $384 \quad$ (2004) 217-226. https://doi.org/10.1016/j.jallcom.2004.04.098.

[19] N. Shevchenko, H. Neumann-Heyme, C. Pickmann, E. Schaberger-Zimmermann, G. Zimmermann, K. Eckert, S. Eckert, Investigations of fluid flow effects on dendritic solidification: Consequences on fragmentation, macrosegregation and the influence of electromagnetic stirring, IOP Conf. Ser.: Mater. Sci. Eng., 228 (2017) 012005. https://doi.org/10.1088/1757-899X/228/1/012005.

[20] M.C. Flemings, Our understanding of macrosegregation: past and present, ISIJ Int., 40 (2000) 833-841. https://doi.org/10.2355/isijinternational.40.833.

[21] C. Beckermann, Modelling of macrosegregation: applications and future needs, Int. Mater. Rev., 47 (2002) 243-261. https://doi.org/10.1179/095066002225006557.

[22] G. Guillemot, C.-A. Gandin, H. Combeau, Modeling of macrosegregation and solidification grain structures with a coupled cellular automaton-finite element model, ISIJ Int., 46 (2006) 880-895. https://doi.org/10.2355/isijinternational.46.880.

[23] W.D. Griffiths, L. Xiao, D.G. McCartney, The influence of bulk liquid natural convection on the formation of the equiaxed regions in $\mathrm{Al}-\mathrm{Cu}$ and $\mathrm{Al}-\mathrm{Si}$ alloys, Mater. Sci. Eng., A, 205 (1996) 31-39. https://doi.org/10.1016/0921-5093(95)09859-3.

[24] G. Zimmermann, C. Pickmann, M. Hamacher, E. Schaberger-Zimmermann, H. Neumann-Heyme, K. Eckert, S. Eckert, Fragmentation-driven grain refinement in directional solidification of AlCu10wt-\% alloy at low pulling speeds, Acta Mater., 126 (2017) 236-250. https://doi.org/10.1016/j.actamat.2016.12.063.

[25] D. Ruvalcaba, R.H. Mathiesen, D.G. Eskin, L. Arnberg, L. Katgerman, In situ observations of dendritic fragmentation due to local solute-enrichment during directional 
solidification of an aluminum alloy, Acta Mater., 55 (2007) 4287-4292. https://doi.org/10.1016/j.actamat.2007.03.030.

[26] B.H. Zhou, H. Jung, N. Mangelinck-Noël, H. Nguyen-Thi, B. Billia, Q.S. Liu, C.W. Lan, Comparative study of the influence of natural convection on directional solidification of Al3.5wt\% Ni and Al-7wt\% Si alloys, Adv. Space Res., 41 (2008) 2112-2117. http://dx.doi.org/10.1016/j.asr.2007.06.038.

[27] J.A. Spittle, Columnar to equiaxed grain transition in as solidified alloys, Int. Mater. Rev., 51 (2006) 247-269. https://doi.org/10.1179/174328006X102493.

[28] A. Hellawell, S. Liu, S.Z. Lu, Dendrite fragmentation and the effects of fluid flow in castings, JOM, 49 (1997) 18-20. https://doi.org/10.1007/bf02914650.

[29] M. Bedel, K.O. Tveito, M. Založnik, H. Combeau, M. M’Hamdi, A model study of the impact of the transport of inoculant particles on microstructure formation during

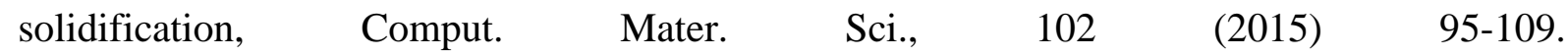
https://doi.org/10.1016/j.commatsci.2015.01.028.

[30] K.O. Tveito, M. Bedel, M. Založnik, H. Combeau, M.M. Hamdi, A. Kumar, P. Dutta, Numerical study of the impact of inoculant and grain transport on macrosegregation and microstructure formation during solidification of an $\mathrm{Al}-22 \% \mathrm{Cu}$ alloy, IOP Conf. Ser.: Mater. Sci. Eng., 33 (2012) 012089. https://doi.org/10.1088/1757-899X/33/1/012089.

[31] L. Heyvaert, M. Bedel, M. Založnik, H. Combeau, Modeling of the Coupling of Microstructure and Macrosegregation in a Direct Chill Cast Al-Cu Billet, Metall. Mater. Trans. A, 48 (2017) 4713-4734. https://dx.doi.org/10.1007/s11661-017-4238-z.

[32] M. Wu, A. Ludwig, Modeling equiaxed solidification with melt convection and grain sedimentation-II. Model verification, Acta Mater., $57 \quad$ (2009) 5632-5644. https://doi.org/10.1016/j.actamat.2009.07.067.

[33] H. Nguyen-Thi, A. Bogno, G. Reinhart, B. Billia, R.H. Mathiesen, G. Zimmermann, Y. 
Houltz, K. Löth, D. Voss, A. Verga, F.d. Pascale, Investigation of gravity effects on solidification of binary alloys with in situ X-ray radiography on earth and in microgravity $\begin{array}{lllllll}\text { environment, } & \text { J. } & \text { Phys: } & \text { Conf. } & \text { Ser., } & 327 & \text { (2011) }\end{array}$ https://doi.org/10.1088/1742-6596/327/1/012012.

[34] A. Kumar, M.J. Walker, S. Sundarraj, P. Dutta, Grain Floatation During Equiaxed Solidification of an Al-Cu Alloy in a Side-Cooled Cavity: Part I-Experimental Studies, Metall. Mater. Trans. B, 42 (2011) 825-836. https://doi.org/10.1007/s11663-011-9518-1.

[35] G. Salloum-Abou-Jaoude, H. Nguyen-Thi, G. Reinhart, R.H. Mathiesen, G. Zimmermann, D. Voss, Characterization of motion of dendrite fragment by X-ray radiography on Earth and under microgravity environment, in: Mater. Sci. Forum Trans Tech Publ, 2014, pp. 311-316. https://doi.org/10.4028/www.scientific.net/MSF.790-791.311.

[36] R. Jansen, P.R. Sahm, Solidification under microgravity, Mater. Sci. Eng., 65 (1984) 199-212. http://dx.doi.org/10.1016/0025-5416(84)90213-1.

[37] D.R. Liu, N. Mangelinck-Noël, C.A. Gandin, G. Zimmermann, L. Sturz, H. Nguyen Thi, B. Billia, Structures in directionally solidified Al-7 wt.\% Si alloys: Benchmark experiments under microgravity, Acta Mater., $64 \quad$ (2014) 253-265. http://dx.doi.org/10.1016/j.actamat.2013.10.038.

[38] S. Akamatsu, H. Nguyen-Thi, In situ observation of solidification patterns in diffusive conditions, $\quad$ Acta $\quad$ Mater., $\quad 108 \quad$ (2016) 325-346. http://dx.doi.org/10.1016/j.actamat.2016.01.024.

[39] G. Zimmermann, L. Sturz, B. Billia, N. Mangelinck-Noel, H.N. Thi, C.A. Gandin, D.J. Browne, W.U. Mirihanage, Investigation of columnar-to-equiaxed transition in solidification processing of AlSi alloys in microgravity-The CETSOL project, in: A. Meyer, I. Egry (Eds.) International Symposium on Physical Sciences in Space, 2011.

[40] G. Zimmermann, L. Sturz, H. Nguyen-Thi, N. Mangelinck-Noel, Y.Z. Li, C.A. Gandin, 
R. Fleurisson, G. Guillemot, S. McFadden, R.P. Mooney, P. Voorhees, A. Roosz, A. Ronafoldi, C. Beckermann, A. Karma, C.H. Chen, N. Warnken, A. Saad, G.U. Grun, M. Grohn, I. Poitrault, T. Pehl, I. Nagy, D. Todt, O. Minster, W. Sillekens, Columnar and Equiaxed Solidification of Al-7 wt.\% Si Alloys in Reduced Gravity in the Framework of the CETSOL Project, Jom, 69 (2017) 1269-1279. https://doi.org/10.1007/s11837-017-2397-4.

[41] Q. Han, S. Viswanathan, Microstructure Prediction in A356 Alloy Castings, In: Peterson RD, editor. Light metals. Warrendale, PA: TMS; , (2008) 609-615.

[42] C.A. Gandin, Experimental study of the transition from constrained to unconstrained growth during directional solidification, ISIJ Int., $40 \quad$ (2000) 971-979. https://doi.org/10.2355/isijinternational.40.971.

[43] C.A. Gandin, From constrained to unconstrained growth during directional solidification, Acta Mater., 48 (2000) 2483-2501. http://dx.doi.org/10.1016/S1359-6454(00)00070-7.

[44] D.G. McCartney, J.D. Hunt, Measurements of cell and primary dendrite arm spacings in directionally solidified aluminium alloys, Acta Metall., 29 (1981) 1851-1863. https://doi.org/10.1016/0001-6160(81)90111-5.

[45] A.L. Greer, A.M. Bunn, A. Tronche, P.V. Evans, D.J. Bristow, Modelling of inoculation of metallic melts: application to grain refinement of aluminium by $\mathrm{Al}-\mathrm{Ti}-\mathrm{B}$, Acta Mater., 48 (2000) 2823-2835. https://doi.org/10.1016/S1359-6454(00)00094-X.

[46] P.S. Mohanty, J.E. Gruzleski, Mechanism of grain refinement in aluminium, Acta Metall. Mater., 43 (1995) 2001-2012. https://doi.org/10.1016/0956-7151(94)00405-7.

[47] D.A. Pineda, M.A. Martorano, Columnar to equiaxed transition in directional solidification of inoculated melts, Acta Mater., $61 \quad$ (2013) 1785-1797. http://dx.doi.org/10.1016/j.actamat.2012.12.002.

[48] M.D. Dupouy, D. Camel, J.J. Favier, Natural convection in directional dendritic solidification of metallic alloys-I. Macroscopic effects, Acta Metall., 37 (1989) 1143-1157. 
http://dx.doi.org/10.1016/0001-6160(89)90110-7.

[49] H. Jung, N. Mangelinck-Noël, H.N. Thi, B. Billia, L. Sturz, G. Zimmerman, Columnar to equiaxed transition in nonrefined Al-based alloys during directional solidification in microgravity and on earth, in: SP07, 5th Decennial International Conference on Solidification Processing, Sheffield, UK, 2007.

[50] S. Karagadde, L. Yuan, N. Shevchenko, S. Eckert, P.D. Lee, 3-D microstructural model of freckle formation validated using in situ experiments, Acta Mater., 79 (2014) 168-180. https://doi.org/10.1016/j.actamat.2014.07.002.

[51] A.G. Murphy, R.H. Mathiesen, Y. Houltz, J. Li, C. Lockowandt, K. Henriksson, G. Zimmermann, N. Melville, D.J. Browne, XRMON-SOL: Isothermal equiaxed solidification of a grain refined $\mathrm{Al}-20$ wt\%Cu alloy, J. Cryst. Growth, 440 (2016) 38-46. https://doi.org/10.1016/j.jcrysgro.2016.01.032.

[52] L. Abou-Khalil, G. Salloum-Abou-Jaoude, G. Reinhart, C. Pickmann, G. Zimmermann, H. Nguyen-Thi, Influence of gravity level on Columnar-to-Equiaxed Transition during directional solidification of Al-20 wt.\% Cu alloys, Acta Mater., 110 (2016) 44-52. http://dx.doi.org/10.1016/j.actamat.2016.03.007.

[53] H. Jung, La transition colonnaire equiaxe au cours de la solidification dirigee d'alliages metalliques, in: L2MP, University of Paul Cezanne, Marseille, France, 2007.

[54] H. Nguyen-Thi, D. Browne, G. Zimmermann, G. Reinhart, A. Murphy, G. Salloum-Abou-Jaoude, A.-K. L, R. Mathiesen, W.H. Sillekens, Overview of in situ X-ray studies of metal alloy solidification in $\mu \mathrm{g}$ conditions - The XRMON project, in: Proceedings of the 6th Decennial International Conference on Solidification Processing (SP17), Old Windsor, UK, 2017, pp. 292-295.

[55] D. Walton, B. Chalmers, The origin of the preferred orientation in the columnar zone of ingots. Trans. Metall. Soc. AIME., 215 (1959) 447-457. 
[56] D. Tourret, Y. Song, A.J. Clarke, A. Karma, Grain growth competition during thin-sample directional solidification of dendritic microstructures: A phase-field study, Acta Mater., 122 (2017) 220-235. https://doi.org/10.1016/j.actamat.2016.09.055.

[57] D. Tourret, A. Karma, Growth competition of columnar dendritic grains: A phase-field study, Acta Mater., 82 (2015) 64-83. https://doi.org/10.1016/j.actamat.2014.08.049.

[58] M.B. Koss, J.C. LaCombe, L.A. Tennenhouse, M.E. Glicksman, E.A. Winsa, Dendritic Growth tip velocities and radii of curvature in microgravity, Metall. Mater. Trans. A, 30 (1999) 3177-3190. https://doi.org/10.1007/s11661-999-0228-0.

[59] M. Schwarz, C.B. Arnold, M.J. Aziz, D.M. Herlach, Dendritic growth velocity and diffusive speed in solidification of undercooled dilute Ni-Zr melts, Mater. Sci. Eng., A, 226 (1997) 420-424. https://doi.org/10.1016/S0921-5093(96)10656-0.

[60] R. Chen, Q. Xu, B. Liu, A Modified Cellular Automaton Model for the Quantitative Prediction of Equiaxed and Columnar Dendritic Growth, J. Mater. Sci. Technol., 30 (2014) 1311-1320. https://doi.org/10.1016/j.jmst.2014.06.006. 